\title{
PROHIBICIÓN DE DISCRIMINACIÓN \\ E INDEMNIZACIÓN POR FINALIZACIÓN \\ DE LOS CONTRATOS DE TRABAJO \\ DE DURACIÓN DETERMINADA
}

\section{RAFAEL GÓMEZ GORDILLO'}

rgomgor@upo.es

Cómo citar/Citation

Gómez Gordillo, R. (2017).

Prohibición de discriminación e indemnización por finalización

de los contratos de trabajo de duración determinada.

Revista de Derecho Comunitario Europeo, 56, 233-255.

doi: https://doi.org/10.18042/cepc/rdce.56.07

Resumen

Los recientes pronunciamientos del Tribunal de Justicia de la Unión Europea relativos a la prohibición de discriminación en el empleo de duración determinada —en aplicación de lo dispuesto en la Directiva 1999/70/CE del Consejo, de 28 de junio de 1999, relativa al Acuerdo Marco de la CES, la UNICE y el CEEP sobre el Trabajo de Duración Determinada - han generado una profunda conmoción entre los operadores jurídicos laborales españoles. El régimen jurídico que regula la finalización de los contratos de interinidad ha sido considerado contrario a la cláusula 4 del Acuerdo Marco sobre el trabajo de duración determinada. El artículo analiza el régimen jurídico aplicable en España al resto de las modalidades contractuales de duración determinada con el fin de valorar si su contenido se ajusta a la doctrina establecida por el TJUE.

\section{Palabras clave}

Indemnización por finalización de contrato; contrato de duración determinada; razones objetivas; condiciones de trabajo; prohibición de discriminación.

1 Profesor titular de Derecho del Trabajo y de la Seguridad Social de la Universidad Pablo de Olavide de Sevilla. 


\title{
PROHIBITION OF DISCRIMINATION AND COMPENSATION FOR TERMINATION OF TEMPORARY EMPLOYMENT CONTRACTS
}

\begin{abstract}
The recent EUCJ judgments on the prohibition of discrimination on fixedterm work -in accordance with the provisions of Council Directive 1999/70/EC, of 28 June 1999, concerning the framework agreement on fixed-term work concluded by ETUC, UNICE and CEEP — have generated a deep shock among Spanish labor legal operators. The legal regime of termination of temporary replacement contracts has been considered contrary to the Clause 4 of the framework agreement on fixedterm work Directive. The paper studies the legal regime applicable to other categories of fixed-term contracts in order to assess if its content is in accordance with the doctrine established by the EUCJ.
\end{abstract}

\section{Keywords}

Compensation for termination of a contract; temporary replacement contract; objective ground; employment conditions; principle of non-discrimination.

\section{INTERDICTION DE LA DISCRIMINATION ET INDEMNITÉ DE RÉSILIATION DU CONTRATS DE TRAVAIL TEMPORAIRE}

\section{Résumé}

Les récents arrêts de la CJCE sur l'interdiction de la discrimination en matière de travail à durée déterminée — conformément à la Directive 1999/70/CE du Conseil, du 28 juin 1999, concernant l'accord-cadre CES, UNICE et CEEP sur le travail à durée déterminée- ont suscité un choc profond chez les opérateurs juridiques du travail espagnols. Le régime juridique de résiliation des contrats de contrats de travail à durée déterminée a été considéré contraire à la clause 4 de l'accord-cadre. Le papier étudie le régime juridique applicable aux autres catégories de contrats à durée déterminée afin d'évaluer si son contenu est conforme à la doctrine établie par la CJUE.

\section{Mot clés}

Indemnité de résiliation d'un contrat; travail à durée déterminée; raisons objectives; conditions d'emploi; principe de non-discrimination. 


\section{SUMARIO}

I. INTRODUCCIÓN. II. EL ÁMBITO DE APLICACIÓN DEL PRINCIPIO DE NO DISCRIMINACIÓN EN EL EMPLEO TEMPORAL: 1. La unidad de tratamiento de las relaciones temporales de trabajo dependiente. 2. El objeto de comparación: trabajo por tiempo indefinido comparable. 3. Las condiciones de empleo y trabajo afectadas. 4. Las razones objetivas que justifican el trato diferenciado. III. LA INDEMNIZACIÓN POR EXTINCIÓN DEL CONTRATO COMO CONDICIÓN DE TRABAJO SOMETIDA AL PRINCIPIO DE NO DISCRIMINACIÓN: 1. La comparabilidad de las causas de extinción. Despido objetivo frente a reincorporación de la persona sustituida. 2. La extensión de las indemnizaciones por causas objetivas al resto de modalidades de contratación determinada. 3. La aplicación de la prohibición de discriminación a las relaciones entre privados en España.

\section{INTRODUCCIÓN}

La Directiva 1999/70/CE sobre el Trabajo de Duración Determinada (en adelante la Directiva) ${ }^{2}$ pretende mejorar las condiciones de trabajo de las personas contratadas bajo esta tipología y el abuso del recurso a lo que se consideran modalidades atípicas de contratación laboral. Sin embargo, el régimen jurídico de la contratación temporal en España permite privar a estas personas de alguna de las ventajas reconocidas a quienes prestan servicio indefinidamente y quizá, por ello, nuestro mercado de trabajo registra tasas de temporalidad superiores a la media de la Unión Europea $(\mathrm{UE})^{3}$. En aplicación del art. 4.3 del Tratado de Funcionamiento de la Unión Europea (TFUE), las autoridades de los Estados miembros que-

2 Directiva 1999/70/CE del Consejo de 28 de junio de 1999 relativa al Acuerdo Marco de la CES, la UNICE y el CEEP sobre el Trabajo de Duración Determinada, DO L 175, de 10 de julio de 1999, p. 43.

3 Según Eurostat, en 2014 la tasa de temporalidad en la UE-28 es del 14\%, en España es del 24\%; esta cifra es inferior solo a la de Polonia que es del 28,3\%. Según los datos del Ministerio de Empleo disponibles en http://www.empleo.gob.es/es/estadisticas/ resumenweb/RUD.pdf consultados por última vez el 3.2.2017), en febrero de 2017 la tasa de temporalidad asciende al 26,5\%. 
dan obligadas a adoptar las medidas necesarias para asegurar los objetivos previstos en las normas ${ }^{4}$; en nuestro país, las Administraciones Públicas (AA PP) son beneficiarias de un alto porcentaje de las irregularidades acreditadas, por más que su condición de empleadoras no las libere del cumplimiento de las obligaciones establecidas por las normas de la $\mathrm{UE}^{5}$. A pesar del largo camino recorrido por el Acuerdo Marco sobre el Trabajo de Duración Determinada (Acuerdo Marco), hasta el pasado mes de septiembre, el Tribunal de Justicia de la Unión Europea (TJUE) no ha tenido oportunidad de pronunciarse sobre su aplicación a los preceptos que regulan la indemnización por finalización del contrato en España, en virtud de la regulación contenida en los artículos 49.1.c y 53.1.b del Estatuto de los Trabajadores $(E T)^{6}$. La Sentencia De Diego Porras ${ }^{7}$ — pronunciada en la misma fecha que otras dos referidas al personal estatutario e interino ${ }^{8}$ - considera contraria al principio de no discriminación la regulación que establece indemnizaciones por despido objetivo, aplicables a personas contratadas indefinida y temporalmente, mientras elude indemnizar a quienes finalizan un contrato de interinidad. La Sentencia ha provocado

4 Sentencias de 13 de septiembre de 2007, Del Cerro Alonso, C-307/05, EU:C:2007:509, apdo. 37; de 22 de diciembre de 2010, Gavieiro Gavieiro e Iglesias Torres, C-444/09 y C-456/09, EU:C:2010:819, apdo. 48; y de 13 de marzo de 2014, Nierodzik, C-38/13, EU:C:2014:152, apdo. 23.

5 Sentencia de 15 de abril de 2008, Impact, C-268/06, EU:C:2008:223, apdo. 41.

6 Real Decreto Legislativo $2 / 2015$, de 23 de octubre, por el que se aprueba el Texto Refundido del Estatuto de los Trabajadores, BOE, núm. 255, de 24 de octubre de 2015, p. 100224.

7 Sentencia de 14 de septiembre de 2016, De Diego Porras, C-596/14, EU:C:2016:683.

8 La Sentencia de 14 de septiembre de 2016, Martínez Andrés, C-184/15 y C-197/15, EU:C:2016:680, considera que la cláusula 5 de la Directiva se opone, en supuestos de utilización abusiva de sucesivos contratos de duración determinada, no se reconozca el derecho a acceder a la condición de indefinido no fijo al personal que presta servicios en régimen de derecho administrativo, a menos que exista otra medida eficaz. Por su parte, la Sentencia de 14 de septiembre de 2016, Pérez López, C-16/15, EU:C:2016:679, considera que la cláusula 5 de la Directiva se opone a la normativa española que permite nombramientos de duración determinada para cubrir necesidades de carácter permanente y estable. Con posterioridad, se conoce el Auto del Tribunal de Justicia de 21 de septiembre de 2016, Álvarez Santirso, C-631/15, EU:C:2016:725; véase Jesús María CHAMORRO GONZÁLEZ, «De nuevo sobre la relación de duración determinada: comentario al Auto del TJUE de 21 de septiembre de 2016, Actualidad Administrativa, núm. 12, 2016. 
una importante polémica con reflejo doctrinal, político y social, y ha sido recibida con rotundos epítetos?

La novedosa doctrina pone en tela de juicio la regulación de una institución, la indemnización por extinción de la relación de trabajo, en torno a la cual ha girado una buena parte del debate sobre el marco jurídico laboral español desde los años ochenta del siglo pasado. Aunque las reformas operadas durante este período han contribuido a reducir las diferencias cuantitativas entre las indemnizaciones por extinción de contrato entre ambos colectivos, hasta la fecha no se había planteado la posibilidad de extender dicha institución a todos los tipos de contratos, especialmente a los que son de aplicación exclusiva en el sector público; ni mucho menos, igualar cuantías que corresponden a fórmulas extintivas con distinta funcionalidad. Una vez que la sentencia se hizo pública, el enfoque antidiscriminatorio ha provocado una auténtica cascada de fallos contra las $\mathrm{AA} \mathrm{PP}^{10}$, inmersas en un intenso

9 Joan AGUSTÍ MARAGAL, «La STJUE Ana de Diego Porras (C-596) y su inmediata recepción y aplicación por los Tribunales españoles: análisis crítico", Iuslabor, 3/2016, pp. 1-32; Ana DE LA PUEBLA PINILLA, «Incertidumbres en torno a la indemnización por finalización de los contratos temporales: (a propósito de la STJUE de 14 de septiembre de 2016, asunto De Diego Porras), Revista de Información Laboral, núm. 9, 2016, pp. 19-32; Aurelio DESDENTADO BONETE, «¿Un miércoles de ceniza para la contratación temporal española? Reflexión breve sobre la Sentencia del Tribunal de Justicia de la Unión Europea en el caso De Diego Porras", Revista de Información Laboral, núm. 10, 2016, pp. 21-32; Joaquín GARCÍA MURCIA, «El trabajo temporal ante el Tribunal de Justicia de la Unión Europea: a propósito de tres llamativas sentencias de septiembre de 2016», La Ley Unión Europea, núm. 41/ 2016; Carlos GONZÁLEZ GONZÁLEZ, «Indemnización a abonar en la extinción de los contratos de interinidad: Análisis de la STJUE de 14 septiembre 2016. Asunto C-596/14 (España), Ana de Diego Porras contra el Ministerio de Defensa», Revista Aranzadi Doctrinal, núm. 11, 2016, pp. 149-176; Manuel Carlos PALOMEQUE LÓPEZ, «Tres sentencias que estremecieron al mundo», Trabajo y Derecho, núm. 23/2016 pp. 1-4; Joaquín PÉREZ REY, «Por una reformulación de nuestro modelo de contratación temporal: reflexiones sobre las consecuencias de la Sentencia Porras en nuestro ordenamiento y la eficacia de la Directiva 99/70», Revista de Derecho Social, núm. 76/2016, pp. 219252; Miguel RODRÍGUEZ-PIÑERO Y BRAVO-FERRER, «La Sentencia del Tribunal de Justicia de la Unión Europea y el régimen indemnizatorio extintivo de los trabajadores interinos», Diario La Ley, núm. 8850, 2016; Antonio V. SEMPERE NAVARRO, «Texto y Contexto de la STJUE sobre indemnización en contratos de interinidad», en Dossier Sentencia TJUE Indemnización a Trabajadores Temporales, Thomson Reuters, 2016, pp. 7-21.

10 SSTSJ de Andalucía de 16 de noviembre de 2016 (rec. 1515/2016 y rec. 1411/2016) y 11 de enero de 2016 (rec. 1827/2016), STSJ de Madrid de 5 de octubre de 2016 
proceso de reducción de plantillas ${ }^{11}$. La onda expansiva provocada por el fallo ha alcanzado también al sector privado, y se ha registrado un buen número de sentencias a favor o en contra de extender dicha doctrina ${ }^{12}$. El Gobierno ordenó la constitución de una Comisión de Expertos, cuyos miembros, a falta de un acuerdo unánime, habrían decidido esperar a que el TJUE resolviera las nuevas cuestiones prejudiciales pendientes ${ }^{13}$, para aclarar los aspectos de su doctrina que presentaban más dudas ${ }^{14}$. En los apartados siguientes, se abordan los problemas que la regulación española plantea desde la perspectiva de la aplicación del principio de no discriminación por razón de la duración del contrato, en los términos que ha sido interpretado por el TJUE, en un intento de anticipar el sentido de los pronunciamientos pendientes y de las reformas normativas futuras ${ }^{15}$.

\section{EL ÁMBITO DE APLICACIÓN DEL PRINCIPIO DE NO DISCRIMINACIÓN EN EL EMPLEO TEMPORAL}

La Directiva prohíbe establecer condiciones menos favorables a las personas contratadas temporalmente con carácter general, pero no impone la igualación de las condiciones de trabajo para todas las personas contratadas

(rec. 264/2014); STSJ de Asturias de 2 de noviembre de 2016 (rec. 1904/2016); STSJ País Vasco de 18 de octubre de 2016 (rec. 1690/16); STSJ Asturias 8 de noviembre de 2016 (rec. 2142/2016); STSJ de Galicia de 26 de octubre 2016.

11 Algunos autores consideran este proceso el artífice de la resurrección de la Directiva: «La crisis económica real —o utilizada en el caso concreto (efectuando extinciones de contratos incluso iniciados en tal circunstancia) — ha comportado la, hasta fechas recientes inédita, existencia de muy numerosas decisiones extintivas contractuales de la Administración pública empleadora de todo tipo de personal, con la pretensión inicial de efectuar amortizaciones de plantillas». Fernando SALINAS MOLINA, «La resurrección de la Directiva 1999/70, CE del Consejo de 28 de junio de 199», Iuslabor, núm. 3/2016, p. 2.

12 SSTSJ País Vasco de 18 de octubre 2016 (rec. 1872/2016), de 15 de noviembre 2016 (rec. 1990/2016), de 22 de noviembre 2016 (1991/2016) y de 22 de noviembre 2016 (rec. 2146/2016) y STSJ de Galicia 30 de noviembre 2016 (rec. 3277/2016).

13 Disponible en http://www.rtve.es/noticias/20170210/expertos-piden-esperar-sentencias-sobre-indemnizacion-interirnos-senalan-error-argumentacion-del-tjue/1489083. shtml (consultado por última vez el 14.2.2017)

14 Auto del TSJ Galicia de 2 de noviembre 2016 (rec. 2279/2016), Auto del JS núm. 33 Madrid de 21 de diciembre 2016 y Auto de JS núm. 2 Terrassa 26 de enero 2017.

15 Un amplio resumen de las dudas interpretativas que la nueva doctrina deja abiertas puede consultarse en SEMPERE NAVARRO, op. cit., p. 20 
por cuenta ajena. La aplicación del Acuerdo Marco se hace depender de una serie de elementos que es preciso delimitar con carácter previo, pues sirven para definir el campo de aplicación del principio de no discriminación en esta materia. En primer lugar, es preciso identificar si una determinada prestación de servicios se encuentra bajo el paraguas protector de la norma. En segundo lugar, se debe seleccionar el término de la comparación, la persona con contrato fijo comparable a la que se dispensaría un mejor trato, lo que se ha dado en llamar juicio de comparabilidad. En tercer lugar, es igualmente necesario delimitar si la medida desigual forma parte del concepto condiciones de trabajo sobre las que la norma no permite un trato diferenciado. Por último, resulta igualmente relevante determinar si la medida objeto de análisis puede o no ser encuadrada en el concepto razones objetivas que, como excepción a la regla general, permite justificar el establecimiento de condiciones de trabajo que perjudican los intereses de las personas contratadas temporalmente.

\section{LA UNIDAD DE TRATAMIENTO DE LAS RELACIONES TEMPORALES DE TRABAJO DEPENDIENTE}

La cláusula 2.1 del Acuerdo Marco establece que sus previsiones son aplicables a todas las personas ligadas a un empleador mediante un contrato de trabajo de duración determinada, independientemente de que dicho contrato haya sido regulado mediante una norma legislativa, convencional o práctica. De esta forma, la norma europea se muestra indiferente a la fuente normativa que regula el contrato. En el caso español, la norma es aplicable a todos los contratos de duración determinada, tanto a los que regula directamente el art. 15 ET como a aquellos que por remisión de este hubiesen sido prorrogados más allá de los límites establecidos en la norma legal por una norma convencional o tuviesen por objeto los «trabajos», «tareas» «actividades» seleccionadas por el convenio colectivo aplicable. Adicionalmente, aunque la cláusula 2.2 del Acuerdo Marco permite excluir a las personas contratadas mediante distintas modalidades de contratos para la formación, inserción o reconversión profesional, la inacción del legislador español coloca los contratos formativos regulados en el art. 11 ET bajo el paraguas de garantías establecido por el Acuerdo Marco, pues su pertenencia a la especie temporal queda fuera de toda duda. Por otra parte, aunque nada dice expresamente la norma sobre la naturaleza pública o privada del empleador, la prohibición de discriminación se extiende a todo tipo de empresas y AA PP. Sobre este particular, el TJUE ha considerado un dato suficiente la amplitud con la que las cláusulas 2.1 y 3.1 del Acuerdo Marco definen las relaciones de trabajo afectadas y, sensu contrario, ha estimado que si el legislador hubiese querido dejar al margen al sector 
público habría debido realizar una referencia expresa, tal y como ha sucedido con la posibilidad de excluir a los contratos formativos ${ }^{16}$.

La anterior afirmación extiende sus efectos también sobre la naturaleza laboral o administrativa de los contratos temporales. A efectos de aplicación, la Directiva únicamente atiende la naturaleza temporal de la relación de trabajo dependiente, siempre que esta contingencia venga determinada por condiciones objetivas tales como «una fecha concreta, la realización de una obra o servicio determinado o la producción de un hecho o acontecimiento determinado» (cláusula 3.1). Con ello, y por lo que respecta a nuestro ordenamiento jurídico, el TJUE ha considerado expresamente incluidos dentro del ámbito de aplicación de la Directiva a los funcionarios interinos, independientemente de la Administración en que presten servicio, al personal estatutario que presta servicios de duración determinada para los servicios de salud ${ }^{17} \mathrm{o}$ a los docentes universitarios contratados temporalmente ${ }^{18}$.

\section{EL OBJETO DE COMPARACIÓN: TRABAJO POR TIEMPO INDEFINIDO COMPARABLE}

La aplicación del principio de no discriminación del trabajo temporal exige, como sucede con el resto de las causas de discriminación prohibidas, la existencia de un trato menos favorable frente a otra situación que es considerada comparable (art. 3.2 del Acuerdo Marco). De esta manera, debe entenderse que no existe discriminación cuando no se produce una identidad entre las tareas que realizan las personas contratadas temporal e indefinidamente. Cabe criticar en este punto la fragilidad de la norma, que no resulta hábil para eliminar todas las diferencias de trato injustificadas que se producen con base en el tipo de contrato de prestación de servicio. La Directiva no se puede aplicar en supuestos en los que la diferencia de trato injustificada se produce

16 Sentencia de 4 de julio de 2006, Adeneler y otros, C-212/04, EU:C:2006:44, apdos. 55, 56 y 57. En el mismo sentido, Sentencia de 7 de septiembre de 2006, Marrosu y Sardino, C-53/04, EU:C:2006:517, apdos. núms. 39, 40, 41 y 42; y Sentencia de 7 de septiembre de 2006, Vassallo, C-180/04, EU:C:2006:518, apdo. 32.

17 Personal a que hace referencia el art. 9 de la Ley 55/2003, de 16 de diciembre, del Estatuto Marco del Personal Estatutario de los Servicios de Salud (BOE, núm. 301, de 17 de diciembre de 2003, p. 44742); Sentencia Pérez López, loc. cit., apdos. 24 y 25.

18 Personal enumerado en el artículo 48 de la Ley Orgánica 6/2001, de Universidades, de 21 de diciembre (BOE, núm. 307, de 24 de diciembre de 2001, p. 49400). Sentencia de 13 de marzo de 2014, Márquez Samohano, C-190/13, EU:C:2014:146, apdo. 39. 
entre distintos contratos de similar duración, esto es, distintos tipos de contratos indefinidos o distintas modalidades de contratos de duración determinada. En el primer caso, el TJUE ha rechazado la posibilidad de oponer los mandatos contenidos en el Acuerdo Marco al contrato de trabajo por tiempo indefinido de apoyo a los emprendedores ${ }^{19}$, pues, como se desprende de su propia denominación, no es un contrato de duración determinada ${ }^{20}$. Por otra parte, el Acuerdo Marco tampoco resulta aplicable cuando las diferencias de trato se producen entre distintas modalidades de contrato de duración determinada ${ }^{21}$. Conviene recordar al respecto que la mejora de las condiciones de vida y de trabajo se ha de producir mediante la aproximación al alza de las condiciones de trabajo, «en particular en lo que respecta a las formas de trabajo distintas del trabajo por tiempo indefinido, como el trabajo de duración determinada, el trabajo a tiempo parcial, el trabajo interino y el trabajo de temporada $»^{22}$. Lege ferenda, la norma debería aplicarse a todo tipo de discriminación que se produzca por causas relacionadas con la modalidad de contratación, no únicamente entre contratos temporales e indefinidos.

\section{LAS CONDICIONES DE EMPLEO Y TRABAJO AFECTADAS}

El Acuerdo Marco no define expresamente qué debe entenderse por condiciones de trabajo, lo que ha permitido desarrollar una doctrina jurisprudencial unificadora de dicho concepto aplicable a todas las directivas que prohíben la discriminación en el empleo ${ }^{23}$, independientemente de la causa que las motiva, con el objetivo de establecer un tratamiento homogéneo, a pesar de que existen importantes diferencias entre el texto de aquéllas y el más sintético

19 Art. 4 de la Ley 3/2012, de 6 de julio, de Medidas Urgentes para la Reforma del Mercado Laboral (BOE, núm. 162, de 7 de julio de 2012, p. 49113)

20 Sentencia de 5 de febrero de 2015, Poclava y otros, C-117/14, EU:C:2015:60, apdo. 38.

21 Auto de 11 de noviembre de 2010, Vino, C-20/10, EU:C:2010:677, apdo. 57.

22 Considerando 3 de la Directiva.

23 Directiva 2000/78/CE del Consejo, de 27 de noviembre de 2000, relativa al establecimiento de un marco general para la igualdad de trato en el empleo y la ocupación (DO L 303, p. 16); Directiva 2006/54/CE del Parlamento Europeo y del Consejo, de 5 de julio de 2006, relativa a la aplicación del principio de igualdad de oportunidades e igualdad de trato entre hombres y mujeres en asuntos de empleo y ocupación (DO L 204, p. 23); Directiva 97/81/CE del Consejo de 15 de diciembre de 1997 relativa al Acuerdo Marco sobre el trabajo a tiempo parcial concluido por la UNICE, el CEEP y la CES sobre el trabajo a tiempo parcial (DO L 14, p. 9) 
que reproduce el Acuerdo $\mathrm{Marco}^{24}$. Esta posición permite alcanzar aspectos de la relación laboral que en una interpretación menos garantista no tendrían cabida. De un lado, se defiende que no cabe realizar interpretaciones restrictivas sobre los principios de derecho social de la $\mathrm{UE}^{25}$; de otro, se rechazan otras tesis que defendían una interpretación extensiva del art. 153.5 TFUE, que excluye de las competencias de la UE en política social las remuneraciones ${ }^{26}$. En aplicación de esta doctrina, el Acuerdo Marco protege los derechos que tengan origen en la relación laboral, como la indemnización por inclusión en un contrato de duración determinada de una cláusula de extinción ilícita ${ }^{27}$, el plazo de preaviso para la resolución de los contratos de trabajo ${ }^{28}$, la fórmula mediante la que se determina el acceso y la cuantía de los complementos salariales por antigüedad ${ }^{29}$, o la contabilización de los períodos trabajados como interino a efectos de promoción interna ${ }^{30}$.

\section{LAS RAZONES OBJETIVAS QUE JUSTIFICAN EL TRATO DIFERENCIADO}

Como excepción a la prohibición general de discriminación, el Acuerdo Marco permite establecer condiciones de trabajo menos favorables cuando exista una razón objetiva que lo justifique. Determinar si existen o no motivos para establecer un trato diferenciado entre personas que realizan el mismo trabajo requiere un análisis de cada caso que permita estudiar las circunstancias específicas que caracterizan la prestación y que, en su caso, pueden justificar en dicho contexto el establecimiento de distintas condiciones ${ }^{31}$. Quienes pretendan otorgar un trato diferenciado deben señalar los elementos que caracterizan la prestación de trabajo de duración determinada frente a la prestación de trabajo indefinida y que determinan la conveniencia y adecuación de otorgar un trato menos favorable al objeto de la consecución de un objetivo legítimo. Solo de esta manera se garantiza que su actuación pueda ser revisada por los órganos jurisdiccionales y, en su caso, considerada ajustada a derecho. En caso contrario, si la justificación no se soporta en elementos objetivos y

\footnotetext{
24 Sentencia Nierodzik, op. cit., apdo. 28.

25 Sentencia Del Cerro Alonso, op. cit., apdos. 41 y 42.

26 Ibid., apdo. 37.

27 Sentencia de 12 de diciembre de 2013, Carratù, C-31-12, EU:C:2013:830, apdos. 36 y 37.

28 Sentencia Nierodzik, op. cit., apdos. 28 y 29.

29 Sentencia Del Cerro Alonso, op. cit., apartado 48; y Sentencia, Gavieiro Gavieiro e Iglesias Torres, op. cit., apdo. 58.

30 Sentencia de 8 de septiembre de 2011, Rosado Santana, C-177/10, EU:C:2011:557

31 Sentencia Del Cerro Alonso, op. cit., apdo. 58
} 
transparentes la medida será considerada contraria al principio de no discriminación establecido en el Acuerdo Marco.

La aplicación de esta doctrina plantea algunos problemas de orden técnico. De un lado, la aplicación del Acuerdo Marco exige que el trabajo a tiempo indefinido comparable sea «idéntico o similar, teniendo en cuenta su cualificación y las tareas que desempeña» (cláusula 3.2); de otro lado, el Acuerdo Marco rechaza que la temporalidad de la relación pueda ser un elemento que se deba valorar a estos efectos (cláusula 4.1). La aplicación conjunta de sendas exigencias dificulta sobremanera la alegación de causas objetivas. Quizá, por ello, el TJUE ha suministrado una trilogía de categorías de razones objetivas: la especial naturaleza de las tareas, las características inherentes a estas y un objetivo de política social ${ }^{32}$. A mi juicio, las dos primeras categorías podrían encuadrarse en una sola, pues las "características inherentes» suelen ser expresiones de la «naturaleza» de las tareas a desarrollar por la persona trabajadora en el cumplimiento de la prestación de trabajo debida. Por el contrario, la tercera de las categorías merece un análisis más detenido. Los objetivos legítimos que pueden perseguir las políticas laborales de los Estados miembros conforman una categoría que puede justificar el establecimiento de diferencias de trato dirigidas a la resolución de todo tipo de problemas que el mercado laboral presenta. Cuando el TJUE señala una categoría tan amplia de razones que justifican la aplicación de una excepción a un principio general debería tener presente el riesgo de vaciarlo de contenido.

En todo caso, la solución de conflictos en los que colisionan diferentes intereses merecedores de la máxima protección suele venir de la mano de la aplicación del test de proporcionalidad. Los argumentos precedentes abonan una exigente aplicación de esta metodología, en los términos establecidos por el «canon reforzado" de proporcionalidad. Con ello, las causas eximentes deberían superar un triple test (idoneidad, necesidad y proporcionalidad) con el fin de verificar si la medida que se propone permite alcanzar el objetivo de política social anunciado y perseguido si las condiciones menos favorables son necesarias, habida cuenta de que para conseguir el objetivo deseado no existe otra solución que afecte en menor medida los derechos de estas personas; y, por último, si existe proporcionalidad entre las lesiones al principio de no discriminación que produce la diferencia de trato y los beneficios de interés general que genera esta ${ }^{33}$. Si bien las resoluciones del TJUE no siempre

32 Sentencia Adelener y otros, op. cit., apdos. 69 y 70.

33 Sobre la aplicación del test de proporcionalidad por el TJUE, véase Josefa FERNÁNDEZ NIETO, La aplicación judicial europea del principio de proporcionalidad, Dykinson, Madrid, 2009. 
reflejan el recurso a esta metodología de manera estricta, un análisis conjunto de su doctrina arroja un balance no falto de interés. En aplicación del test de proporcionalidad, se ha rechazado que la naturaleza de la fuente que establece el trato diferenciado resulte relevante en la aplicación del principio de no discriminación, porque el hecho de que esta sea una norma legal o un acuerdo colectivo no le dota per se de objetividad ${ }^{34}$. Tampoco ha sido admitida la razonabilidad de una medida justificada en la propia naturaleza temporal de la relación de servi$\operatorname{cios}^{35}$, pues es precisamente esta la prohibición que establece la norma.

En la aplicación del principio de proporcionalidad, ha sido también rechazada una medida que se justificaba en el interés de evitar que se produzcan discriminaciones inversas. Aunque se considera que podría tratarse de una razón objetiva, se estima que la medida resulta desproporcionada porque excluye "por completo y en cualquier circunstancia que se tomen en consideración los períodos de servicio prestados por los empleados públicos en el marco de relaciones de servicio de duración determinada para determinar su antigüedad $y$, por tanto, su nivel retributivo» ${ }^{36}$. De esta manera, la doctrina del TJUE permite considerar contrarias a las disposiciones de la Directiva aquellas medidas que, persiguiendo un objetivo legítimo y siendo adecuadas a efectos de su consecución, puedan desbordar la consecución de dicho objetivo e infligir una restricción excesiva e innecesaria de los intereses de las personas contratadas temporalmente.

\section{LA INDEMNIZACIÓN POR EXTINCIÓN DEL CONTRATO COMO CONDICIÓN DE TRABAJO SOMETIDA AL PRINCIPIO DE NO DISCRIMINACIÓN}

La Sentencia De Diego Porras aborda la aplicación del principio de no discriminación a las extinciones por finalización de contrato de duración determinada, en un supuesto de resolución de un contrato de interinidad por reincorporación de la persona sustituida (art. 15.1.c ET) ${ }^{37}$. En la aplicación de la doctrina que hemos analizado en los apartados anteriores, el TJUE conside-

34 Sentencias Del Cerro Alonso, op. cit., apdo. 57; Gavieiro Gavieiro e Iglesias Torres, op. cit., apdo. 54; Rosado Santana, op. cit., apartado 72; y Valenza y otros, op. cit., apdo. 50.

Sentencias Gavieiro Gavieiro e Iglesias Torres, op. cit., apdos. 56 y 57; Rosado Santana, op. cit., apdo. 74; y Valenza y otros, op. cit., apdo. 52.

36 Sentencia Álvarez Santirso, op. cit., apdo. 57.

37 El cese de la situación, dispensa de obligaciones laborales para la realización de funciones sindicales, que da origen a la suspensión del contrato se produce por aplicación del Real Decreto-ley 20/2012, de 13 de julio, de medidas para garantizar la estabilidad 
ra que la indemnización por finalización del contrato temporal se encuentra comprendida en el concepto de condiciones de trabajo que determina el ámbito de aplicación del Acuerdo Marco (apdo. 31), que el marco normativo laboral español concede un trato desfavorable para las personas contratadas como interinas (apartado 36), que la señora De Diego Porras realizaba un trabajo idéntico o similar al realizado por las personas con contrato indefinido (apdo. 44), que la previsibilidad de la finalización del contrato de interinidad no es una razón objetiva que permite considerar justificada la diferencia de trato (apdo. 51) y, por todo lo anterior, que el régimen jurídico aplicable es contrario a las disposiciones contenidas en la cláusula 4 del Acuerdo Marco (apdo. 52).

La cuestión de mayor relevancia tiene por objeto determinar si es jurídicamente adecuado o no dispensar un trato similar a instituciones extintivas de distinta naturaleza, como son las que permiten darlo por terminado por cumplimiento del término extintivo o de la condición resolutoria acordados, frente a aquellas otras que permiten extinguir un contrato por las causas objetivas establecidas en el art. $52 \mathrm{ET}^{38}$. Una vez resuelto el dilema anterior en sentido positivo, convendría determinar si la igualación en las cuantías indemnizatorias debe realizarse con relación a todas las modalidades contractuales de duración determinada, teniendo en cuenta que el art. 49.1.c ET ya establece para algunas de ellas una indemnización inferior a la establecida por el art. 53.1.b ET para la extinción por causas objetivas (doce días por año trabajado frente a veinte) o únicamente sobre aquellas para las que la normativa no prevé indemnización alguna (contrato de interinidad, contratos para la formación). Por último, es preciso determinar si la prohibición de trato desigual a las personas contratadas temporalmente puede aplicarse a las relaciones laborales desarrolladas en el sector privado o si es preciso aguardar la reforma de la normativa española.

\section{LA COMPARABILIDAD DE LAS CAUSAS DE EXTINCIÓN. DESPIDO OBJETIVO FRENTE A REINCORPORACIÓN DE LA PERSONA SUSTITUIDA}

La Sentencia De Diego Porras impone reconocer la indemnización establecida por la norma para el despido objetivo a las personas cuyos contratos

presupuestaria y de fomento de la competitividad (BOE, núm. 168, de 14 de julio de 2012, p. 50428), Sentencia De Diego Porras, op. cit., apdo. 16.

38 A modo de ejemplo, como es conocido la regulación en la materia prevé la posibilidad de extinguir el contrato de trabajo por muerte o jubilación del empleador (art. 49.1.g ET), una modificación sustancial de las condiciones de trabajo (art. 41.3 ET), por voluntad del trabajador fundada en incumplimientos contractuales del empleador (art. 50 ET). 
interinos finalicen por reincorporación de la persona sustituida, si bien por aplicación analógica esta misma solución ha sido aplicada a supuestos de extinción de de dicho contrato por cobertura o amortización de la plaza ${ }^{39} \mathrm{y}$ ante la resolución de otro tipo de contratos ${ }^{40}$. La figura del despido objetivo engloba causas que afectan tanto a la empresa y su evolución (económicas, técnicas, organizativas o productivas, insuficiencia de consignación presupuestaria de programas financiados por las AA PP) como a la persona trabajadora y sus circunstancias personales (absentismo) o profesionales (ineptitud sobrevenida, falta de adaptación a modificaciones técnicas). Si es posible o no, a los efectos de aplicación del Acuerdo Marco, considerar comparables ambas instituciones y es una cuestión sobre la que no se detiene a reflexionar el TJUE, ni en el momento de realizar la verificación de la coexistencia de un tratamiento diverso (apdo. 36), ni a la hora de analizar la existencia de una causa objetiva que justificase la diferenciación (apdo. 45 y ss.) Aunque la Sentencia no desciende a enjuiciar con la profundidad que merecen estos extremos, sí aborda de manera sucinta la cuestión cuando estudia la existencia de razón objetiva, en particular, cuando responde a las alegaciones realizadas por la representación del Gobierno español. Para las autoridades españolas, el marco jurídico sería respetuoso con el Acuerdo Marco habida cuenta de que la persona contratada como interina consintió en el momento de suscribir el contrato en darlo por finalizado cuando la persona sustituida se reincorporase a su puesto de trabajo, motivo por el cual no se ha producido ningún daño que merezca ser compensado con una indemnización, pues el interino da su conformidad y conoce desde el primer momento que sus contrato está sometido a un término de naturaleza incierta. En suma, en el caso de las personas contratadas por tiempo indefinido existe una expectativa de estabilidad del empleo de la que no disfrutan las personas contratadas temporalmente en las que por el contrario subyace la previsión de finalización cierta (apdo. 48).

El TJUE rechaza los argumentos de la Administración española y considera que la mayor previsibilidad de la finalización de estos contratos no está soportada por criterios objetivos y transparentes (apdos. 49 y 50). Como se

39 STSJ de Asturias de 2 de noviembre 2016 (rec. 1904/2016); SJS núm. 20 Barcelona 7 de diciembre 16 (núm. 223/16)

40 Entre otras, con relación a las personas contratadas como eventuales del sector público: SSTSJ de Andalucía/Málaga de 16 de noviembre de 2016, rec, 1532/2016, rec. 1515/2016 y rec. 1411/2016; STSJ de AndalucíalMálaga de 11 de enero 2017 (rec. 1827/16); con relación a los contratos de obra o servicio determinado: STSJ País Vasco 18 de octubre 2016 (rec. 1690/16); con relación a los contrato indefinidos no fijos: STSJ de Asturias 8 de noviembre 2016 (rec. 2142/2016) y STSJ de Galicia 26 de octubre 2016 (rec. 2059/2016). 
ha dicho más arriba, la objetivación de la causa exige concretar qué características definen la indemnización por despido objetivo en el sistema español y por qué no resulta adecuado o conveniente anudar dicha indemnización a la finalización del contrato de interinidad. No cabe duda de que en el caso del litigio - pero también en otros muchos casos- el contrato de interinidad puede perpetuarse durante largos períodos de tiempo, incluso permitir la jubilación de la persona en dicho puesto. Pero existe otro elemento que pesa en la decisión con mayor fuerza si cabe: la falta de coherencia que existe entre el argumento de la mayor previsibilidad de la finalización del contrato de interinidad y la fijación de compensaciones para otras modalidades contractuales de menor duración media, como es el caso de los contratos eventuales y de obra o servicio. Esta contradicción permite al TJUE afirmar que la decisión de fijar o no indemnizaciones por terminación de contratos en el marco normativo español no está relacionada con la mayor o menor duración de los contrato, o la previsibilidad de su finalización (apdo. 51).

Sin perjuicio de lo anterior, en el marco normativo de la contratación laboral existen otros elementos que apuntarían hacia la inexistencia de criterios objetivos y transparentes de diferenciación entre instituciones extintivas formalmente diversas. Es por ello que, completando la labor realizada por el TJUE, considero necesario, de manera obligadamente breve, analizar las diferentes instituciones extintivas reguladas por el ET y relacionarlas con las compensaciones económicas correspondientes. El régimen jurídico que determina las formas de finalización del contrato de trabajo y que establece la cuantía de las indemnizaciones con carácter general se encuentra en los arts. 49 a 56 ET. En un primer acercamiento, pudiera suponerse que el art. 49 ET establece todas las causas de extinción ${ }^{41}$. Sin embargo, dicho precepto enumera solo una serie incompleta de motivos que permiten la extinción del contrato de trabajo en las que encontramos causas extintivas adoptadas por acuerdo de las partes, causas de finalización del contrato por voluntad unilateral del trabajador, extinciones del contrato basadas en la imposibilidad material de continuarlo por muerte o jubilación del trabajador o del empleador y, por último, causas de extinción soportadas en la voluntad unilateral del empleador. Con mejor sistemática, el art. 50 ET enumera las causas de extinción por voluntad unilateral del trabajador, si bien hace referencia únicamente a las que tienen origen en un incumplimiento grave de las obligaciones empresariales, compensando a los trabajadores con la misma indemnización prevista para los despidos

41 Mercedes SANCHA SÁIZ, "Artículo 49: Extinción del contrato», en AA VV, Comentarios al Estatuto de los Trabajadores, Lex Nova, Navarra, 2016, pp. 630-644. 
improcedentes (arts. 50.2 y 56.1 ET) ${ }^{42}$. Pero existe otra causa de extinción por voluntad del trabajador que tiene origen no exactamente en un incumplimiento empresarial, pero sí en la novación del contrato operada unilateralmente por este. Se trata de la posibilidad establecida en el art. $41.3 \mathrm{ET}^{43}$, que ha de ser compensada con una indemnización similar a la establecida para los despidos objetivos. Por último, aunque no se trata de extinciones que responden a la voluntad unilateral del trabajador, las situaciones de muerte e invalidez del empleador son compensadas con una indemnización específica y no progresiva (art. 49.1.g ET), eso sí, siempre que no se dé continuidad a la actividad empresarial por otra persona.

Por otra parte, entre las extinciones por voluntad del empleador, cabe distinguir entre las que se justifican en incumplimientos contractuales del trabajador y las que tienen origen en causas netamente empresariales. Entre las primeras, los incumplimientos graves y culpables darían lugar a un despido disciplinario (art. $54 \mathrm{ET})^{44}$, que lógicamente no se compensa con cantidad alguna. Pero la norma prevé otro tipo de incumplimientos, estos muchos más leves —en absoluto culpables e, incluso, alguno absolutamente justificados - que afectan al trabajador (ineptitud sobrevenida, falta de adaptación al puesto, absentismo, invalidez permanente total, absoluta o gran invalidez) y que permiten el despido de las personas afectadas por decisión unilateral del empleador, con distintas cuantías indemnizatorias. En concreto, los tres primeros supuestos son considerados despidos objetivos, por lo que reciben la indemnización prevista en el art. 53.1.b ET; los siguientes motivos se excluyen de dicha calificación y no reciben indemnización legal alguna, y ello aunque la incapacitación para el trabajo tenga origen en una contingencia de carácter profesional (enfermedad profesional o accidente de trabajo). Siendo así, no es extraño que un buen número de convenios colectivos prevean algún tipo de medida compensatoria, habitualmente a través de la concertación de un seguro $^{45}$. Estas carencias podrían justificarse en el hecho de que la declaración

42 Mercedes SANCHA SÁIZ, «Artículo 50. Extinción por voluntad del trabajador», en AA VV, Comentarios al Estatuto de los Trabajadores, Lex Nova, Navarra, 2016, pp. 644-656.

43 Jesús CRUZ VILLALÓN, Rafael GÓMEZ GORDILLO, «Artículo 41. Modificaciones sustanciales de las condiciones de trabajo», en AA VV, Comentarios al Estatuto de los Trabajadores, Lex Nova, Navarra, 2016, pp. 509-522.

44 Ana María BADIOLA SÁNCHEZ, "Artículo 54. Despido disciplinario», en AA VV, Comentarios al Estatuto de los Trabajadores, Lex Nova, 2016, pp. 722-732.

45 Rafael GÓMEZ GORDILLO, «El tratamiento de las enfermedades profesionales en la negociación colectiva», en AA VV, Las Enfermedades Profesionales, Tirant Lo Blanc, Valencia, 2017, pp. 443-471. 
de incapacidad determina el cobro de una pensión de carácter vitalicio que hace superfluo el recurso a una indemnización por finalización del contrato; en contra, debe señalarse que no en todos los supuestos se verifica esta posibilidad; pues, en el caso de enfermedad común, es preciso acreditar un período de cotización previo, pero sobre todo debe advertirse que la compensación no está relacionado con un daño real sino presunto. Las indemnizaciones por pérdida de empleo no se gradúan en función de las mayores o menores expectativas de encontrar un nuevo trabajo, ni atendiendo a su situación económica y, a mayor abundamiento, la prestación por desempleo tiene un objetivo similar al de la indemnización por finalización del contrato, y el derecho a percibirla no interfiere en nada en el derecho al pago de la indemnización por despido ni en la modulación de su cuantía. Para finalizar, estarían las causas empresariales (art. 51.1 ET) que, aunque en algunas ocasiones son consideradas una respuesta a situaciones de crisis, no siempre responden a una situación empresarial negativa o patológica. En ocasiones, son decisiones empresariales de cambio en la organización, en los medios o instrumentos de producción o en los productos o servicios que la empresa pone en el mercado; transformaciones que pueden o no estar impulsadas por circunstancias desfavorables. En tales casos, las personas afectadas recibirán la indemnización prevista en el art. 53.1.b ET. La misma indemnización se establece en supuestos de fuerza mayor (art. 49.1.h ET).

Pues bien, del breve repaso de estos preceptos pueden extraerse algunas conclusiones. La compensación por despido no está relacionada con la persona que toma la decisión extintiva — pues se reconocen tanto ante decisiones unilaterales del trabajador como del empleador- ni tiene origen en la causa que habilita la decisión, pues en ocasiones se reconocen ante incumplimientos contractuales del empleador, ante incumplimientos no culpables del trabajador y ante situaciones en que ninguna de las partes posee responsabilidad alguna. La indemnización tampoco está relacionada con la duración del contrato, si bien en la mayoría de supuestos su cuantía se calcula atendiendo a la antigüedad en la empresa, de forma que su monto es directamente proporcional al número de años trabajado. De esta forma, aunque estos preceptos resultan aplicables por igual a la extinción de contratos fijos y temporales, la forma de cálculo perjudica a quienes realizan prestaciones de trabajo de escasa duración, si bien es cierto que en algún supuesto, como el de muerte o jubilación del empleador, la indemnización no es creciente. En todo caso, la cuantía de la indemnización no está relacionada ni con la mayor o menor dificultad de encontrar un empleo, ni con la existencia de prestaciones públicas o privadas de seguridad social que puedan compensar el daño causado, ni con la situación de necesidad real que la extinción del contrato genera. De esta forma, la indemnización de veinte días por año trabajado, con un máximo 
de doce mensualidades, puede ser considerada la compensación tipo entre nosotros. Con todo, estimo que existen elementos suficientes para afirmar que el sistema español de indemnizaciones por finalización de la relación de trabajo no ha sido edificado sobre criterios dotados de la suficiente objetividad y transparencia, habida cuenta de que el diseño de las causas habilitantes y de las indemnizaciones que en cada caso corresponden han sido elaboradas para responder a opciones de política normativa dirigidas a la consecución de objetivos que no superan el juicio de proporcionalidad, en términos de idoneidad, necesidad y proporcionalidad. Buena prueba de esta afirmación es el caso de los contratos de interinidad que reciben el mismo tratamiento legal que el despido disciplinario.

Pues bien, dicho lo anterior, conviene ahora repensar si, efectivamente, como afirma el Gobierno español, quien suscribe un contrato de interinidad conoce y consiente que su duración está sometida a condición y, por tanto, su conclusión no sufre daño compensable, pues la ruptura de la relación es conocida y esperada por el trabajador. Si se parte de la condición, es un acontecimiento incierto que puede o no suceder en el futuro, y que esta modalidad contractual no incluye por disposición legal un período máximo de duración, la expectativas de la persona trabajadora dependen de una serie de circunstancias de difícil aprehensión, relacionadas en particular con los hechos que rodean a la causa de la suspensión del contrato que determina el derecho a reserva de puesto de trabajo. La reincorporación de la persona sustituida es un evento sobre el que resulta arriesgado realizar previsiones, ya que no se conoce previamente si se producirá y, de producirse, no se sabe en qué fecha. La misma reflexión puede realizarse respecto de las interinidades por vacante, para las que la decisión de sacar la plaza a concurso está relacionada con circunstancias que escapan al juicio de previsibilidad. Por otra parte, tampoco es enteramente cierto que la incorporación de la persona sustituida determine en todo caso la finalización del contrato, pues, cuando la persona sustituta continúa prestando servicios una vez que se extingue el derecho a reserva de puesto de trabajo, su relación de laboral se convierte en indefinida (art. 49.1.c ET). De esta forma, la continuidad de la relación de trabajo de la persona interina puede o no solucionarse por distintos motivos, si bien siempre queda sometida a la voluntad de una de las partes, el empleador. Dicho en otros términos, el contrato de interinidad es un contrato sometido a una condición resolutoria que no proyecta efectos extintivos de manera automática, pues la actualización de la condición únicamente habilita al empleador a dar por terminado el contrato; de esta forma, la resolución no se produce de manera consensuada o de mutuo acuerdo, sino de forma unilateral.

Si se procede a analizar la formulación de las causas de despido objetivo, se pueden alcanzar similares conclusiones, pues sus causas actúan de manera 
análoga. Si es o no previsible que durante la ejecución de un contrato laboral pueda superarse el número de ausencias que establece la norma, es una variable relacionada con el límite cuantitativo que establece el precepto, con la salud del colectivo y de la persona afectada, no con la naturaleza de la condición; la ineptitud sobrevenida y la falta de adaptación están ligadas a las capacidades y competencias de la persona y a la evolución de las tareas que realiza en la empresa; por último, se han ampliado tanto las causas empresariales que con bastante certeza aparecerán en algún momento en toda carrera profesional. Pero lo que estimo de mayor relevancia a los efectos del juicio de comparación es que en todos estos supuestos, en términos formales, nos encontramos ante acontecimientos inciertos conocidos por las partes: unas condiciones resolutorias asumidas en el momento de la firma del contrato. A mayor abundamiento, como en el caso de finalización del contrato de interino, las causas agrupadas bajo el concepto de despido objetivo tampoco operan de manera automática, de forma que la decisión de extinguir un contrato de trabajo, temporal o indefinido, tanto si existe causa como si no, corresponde al empleador. Si existe causa el quantum de la indemnización es inferior; si no existe causa, el legislador permite la extinción del contrato, pero eleva la cuantía de aquella. Únicamente se impide al empleador materializar su voluntad extintiva cuando el despido lesiona derechos fundamentales, es discriminatorio o está relacionado con la maternidad o los cuidados familiares (art. 55.5 ET) ${ }^{46}$. A la vista del régimen jurídico de la extinción del contrato expuesto, resulta difícil explicar la inexistencia de indemnizaciones sobre la base del cálculo de probabilidades de actualización de la condición establecida entre los dos supuestos extintivos objeto de comparación. La incertidumbre que introduce la condición resolutoria - junto a la inexistencia de una duración máxima del contrato- genera una expectativa de estabilidad similar a la que ofrecen los contratos de duración indefinida.

\section{LA EXTENSIÓN DE LAS INDEMNIZACIONES POR CAUSAS OBJETIVAS AL RESTO DE MODALIDADES DE CONTRATACIÓN DETERMINADA}

Una de las dudas más recurrentes sobre el contenido de la Sentencia De Diego Porras, se refiere a la posibilidad de extender su doctrina a todo tipo de contratos de duración determinada, en particular a aquellos que con mayor

46 María Nieves MORENO VIDA, José Luís MONEREO PÉREZ, "El despido nulo», en AA VV, Modalidades de extinción del contrato de trabajo. Análisis de su régimen jurídico, Comares, Granada, 2014, pp. 85-147. 
frecuencia son utilizados en nuestro sistema de relaciones laborales ${ }^{47}$. Algunos tribunales españoles se han mostrado ya partidarios de esta posibilidad ${ }^{48}$, si bien algunos otros han considerado contraria a derecho tal equiparación ${ }^{49}$. A diferencia de lo que ocurre con los contratos de interinidad, la norma legal sí establece períodos máximos de duración para los contratos eventuales (art. 15.1.b ET) y por obra o servicio determinado (art. 15.1.a ET), y una compensación a su finalización (art. 49.1.c ET). En ambos casos, los contratos de trabajo de duración determinada han sido diseñados como negocios jurídicos sometidos a término final (término cierto en el primer caso, incierto en el segundo). La aceptación por parte del trabajador de estas modalidades en principio conlleva un mayor grado de certeza sobre la temporalidad de la relación de trabajo, lo que podría constituir una valoración diferente con respecto a la razonabilidad y objetividad de la causa. Sin embargo, también respecto de estos contratos conviene detenerse a analizar con mayor profundidad el régimen jurídico de la extinción.

El contrato eventual puede extender su duración por un período de hasta seis meses, salvo que dicho período haya sido ampliado vía convenio colectivo, de esta forma la norma convencional puede habilitar la firma de contratos de hasta un año de duración (art. 15.1.b ET). Por su parte, por disposición legal, los contratos de obra o servicio determinado no pueden superar los tres años de duración, aunque pueden llegar a alcanzar cuatro si así lo establece el convenio (art. 15.1.a ET). Pues bien, ni la superación de la fecha indicada como término ni la finalización del trabajo contratado determinan por sí solas la finalización de estos contratos, pues la norma legal exige una denuncia expresa, en cuya ausencia y ante la continuidad de la relación de trabajo el contrato puede ser prorrogado o convertido en indefinido (art. 49.1.c ET). De esta forma, la certeza sobre el fin del contrato está lejos de manifestar el carácter

47 Según los datos ofrecidos por el SEPE, de los 1,4 millones de contratos de duración determinada celebrados el pasado mes de enero, 0,64 millones fueron por obra o servicio determinado y 0,67 eventuales por circunstancias de la producción. Dsiponible en https:// www.sepe.es/contenidos/que_es_el_sepe/estadisticas/datos_avance/pdf/contratos/ evolconindef_temp.pdf (consultado por última vez el 9.2.2017).

Entre otras, han reconocido la indemnización de veinte días por año trabajado a la extinción de contratos de obra o servicio la STSJ del País Vasco de 18 de octubre de 2016 (rec. 1872/2016), la STSJ de Galicia de 30 de noviembre de 2016 (rec. 3277/2016); los mismos efectos se reconocen en supuestos de extinción de contratos eventuales en la STSJ del País Vasco de 22 de noviembre de 2016 (rec. 2146/2016).

Entre otras, no han reconocido la indemnización de veinte días por año trabajado a la extinción de contratos de obra o servicio la STSJ de Andalucía/Málaga de 16 de noviembre 2016 (rec. 1539/2016). 
absoluto que se le supone, pues la norma la hace depender de la voluntad del empleador. En todo caso, como se ha dicho con anterioridad, el legislador ha decido reconocer a estos trabajadores una indemnización por finalización del contrato, con el objetivo de desincentivar el abuso de estas modalidades contractuales, por lo que llegados a este punto la cuestión muestra diferencias con la debatida en el apartado anterior, pues se trata de determinar si la mayor previsibilidad de la finalización de estos contratos y el hecho de que la extinción de contratos indefinidos y de interinidad esté sometida a condición, mientras que los contratos eventuales y de obra están sometidos a un término (cierto en un caso, incierto en el otro) son causa suficiente, dotada de objetividad y transparencia, para establecer diferencias cuantitativas con las indemnizaciones previstas para el despido objetivo.

La respuesta en mi opinión ha de ser negativa, no solo porque la certeza sobre la finalización del contrato es un elemento cargado de subjetividad, sino porque como se ha expuesto en el apartado anterior el marco normativo español en la materia adolece de falta de sistemática, lo que impide conocer los objetivos que el legislador ha buscado estableciendo indemnizaciones de cuantía diferenciada. Estos contratos son, sin duda, un ejemplo de ello, en la medida en que el argumento de la mayor previsibilidad de la finalización a corto plazo del contrato debiera conducir a la eliminación de todo tipo de compensación. Sin embargo, en esta ocasión la fijación de una indemnización posee un carácter significativamente distinto, pues tiene por objeto desincentivar el uso de estas modalidades contractuales. Por ello y porque, como ha dicho el TJUE, el principio de no discriminación no ha de ser objeto de interpretaciones restrictivas, considero que el Acuerdo Marco sería también contrario a la norma española que establece cuantías indemnizatorias diferenciadas en supuestos de despido objetivo para los contratos indefinidos y por finalización del contrato en supuestos de contratos de obra o servicio determinado o contratos eventuales. Sin perjuicio de lo anterior, una reforma normativa que estableciese un régimen sistematizado de compensaciones por finalización de contratos, en el que las causas y los efectos queden ordenados de manera objetiva y transparente, podría superar el test de proporcionalidad, siempre que el fin perseguido con estas medidas fuese legítimo, que las distintas causas y montos de indemnización contribuyesen a su consecución, que pudiese acreditarse que no existen otras fórmulas más adecuadas para lograr dichos objetivos y, por último, que las diferencias entre las distintas cuantías sean proporcionadas. Con relación a los contratos formativos (art. 11 ET), su especial objeto y la causa, en los que se funden elementos de aprendizaje y prestacionales, impiden superar el juicio de comparabilidad, pues en este caso el trabajo de duración determinada no ha de ser idéntico ni similar al indefinido. El hecho de que el propio Acuerdo Marco permita a los Estados miembros 
excluir estas modalidades es un indicio sólido de la especial consideración que dicho contratos poseen entre los de duración determinada.

\section{LA APLICACIÓN DE LA PROHIBICIÓN DE DISCRIMINACIÓN A LAS RELACIONES ENTRE PRIVADOS EN ESPAÑA}

Una vez que el TJUE ha determinada la deficiente o incompleta transposición de la directiva al ordenamiento jurídico laboral español, es preciso plantearse la posibilidad y adecuación de aplicar dicha doctrina a las relaciones de trabajo en el sector privado. La eficacia directa del derecho de la UE se halla limitada por la fuente mediante la que se expresa, por lo que solo pueden ser directamente invocadas ante los tribunales nacionales las normas de derecho originario y los reglamentos de la UE (art. $97 \mathrm{TFUE})^{50}$. Sin perjuicio de lo anterior, los particulares pueden invocar las Directivas no transpuestas frente al Estado incumplidor, eficacia directa vertical ${ }^{51}$, y siempre que estas impongan obligaciones en términos inequívocos ${ }^{52}$, incondicionados y suficientemente precisos ${ }^{53}$.

En aplicación de esta doctrina, la Directiva no podría ser invocada en las actuales circunstancias ante los tribunales españoles en pleitos relativos al sector privado, sin perjuicio de las responsabilidades que puedan exigírsele al Estado incumplidor. Cerrado el paso a la posibilidad de reconocer eficacia horizontal a la directiva, el TJUE ha aceptado en ocasiones la invocación de los derechos fundamentales de la UE que estas desarrollan, en particular respecto del principio general de no discriminación por razón de edad. En este sentido, es una doctrina consolidada el hecho de que las directivas que regulan el principio de igualdad de trato en el empleo no establezcan dicho principio, habida cuenta de que este es reconocido en instrumentos internacionales y en las tradiciones constitucionales comunes a los Estados miembros. De esta manera, la función de las directivas antidiscriminación sería la de establecer

50 Sentencia de 5 de febrero de 1963, Van Gend en Loos, C- 26/62, EU:C:1963:1

Sentencia de 23 de febrero de 1994, Difesa della Cava, C-236/92, EU:C:1994:60.

Sentencia de 4 de diciembre de 1974, Van Duyn, C-41/74, EU:C:1974:133; Sentencia de 15 de julio de 1982, Rickmer, C-270/81, EU:C:1982:281; Sentencia de 19 de enero de 1982, Becker, C-8/81, EU:C:1982:7. Para un estudio de esta doctrina, véase Lucía MILLÁN MORO, "La eficacia directa de las directivas: evolución reciente», Revista de Instituciones Europeas, vol. 18, núm. 3/1991, pp. 845-882; sobre su aplicación en el ámbito laboral, véase Icíar ALZAGA RUIZ, La eficacia de las directivas comunitarias en el ámbito laboral, Aranzadi, Navarra, 2009. 
un marco normativo de represión de las diferencias de trato basadas en determinadas causas ${ }^{54}$.

Casi con toda seguridad, al responder las cuestiones prejudiciales pendientes en la materia el TJUE deberá pronunciarse sobre si la discriminación por duración del contrato forma parte también de ese principio general del derecho de la UE, para, con ello, aclarar si la Directiva cumple un mero papel de concreción de dicho principio o, si por el contrario, es la fuente de dicha prohibición. La amplitud con la que el art. 21.1 de la Carta de Derechos Fundamentales de la Unión Europea reconoce dicho principio permite esperar una resolución favorable a la primera interpretación, aunque en el caso del trabajo de duración determinada no exista una mención expresa en la norma. A favor de esta tesis obraría el hecho de que el precepto realiza una prohibición de discriminación general, no específica para el ámbito del empleo, por lo que difícilmente podría haberse referido a la modalidad contractual. En caso contrario, podría quedarse al margen de la aplicación directa de este principio en el ámbito de las relaciones de trabajo una de las causas más frecuentes de discriminación que, por otra parte, suele afectar de manera más intensa a algunos de los grupos a los que sí hace referencia la norma, convirtiéndose en un índice multiplicador de los efectos negativos de la discriminación. En todo caso, e independientemente de la posición que finalmente el TJUE adopte sobre este punto, en aplicación del Acuerdo Marco o del principio general de no discriminación, el legislador español está obligado a reformar el régimen jurídico de las indemnizaciones por finalización de contrato, para hacer depender su fijación y cuantía de causas objetivas y transparentes, único camino para cumplir adecuadamente con la normativa europea.

54 Sentencia de 22 de noviembre de 2005, Mangold, C-144/04, EU:C:2005:709, apdo. 74. 
